\title{
EUROSTERONE MEETING
}

\section{Neuroendocrine regulation of autoimmune/inflammatory disease}

\author{
E M Sternberg
}

NIMH/NIH, Building 10, Room 2D-46, 10 Center Drive, MSC 1284, Bethesda, Maryland 20892, USA

\begin{abstract}
Interactions between the immune and nervous systems play an important role in modulating host susceptibility and resistance to inflammatory disease. Neuroendocrine regulation of inflammatory and immune responses and disease occurs at multiple levels: systemically, through the anti-inflammatory action of glucocorticoids released via hypothalamic-pituitary-adrenal axis stimulation; regionally, through production of glucocorticoids within and sympathetic innervation of immune organs such as the thymus; locally, at sites of inflammation. Estrogens also play an important role in immune modulation, and contribute to the approximately 2 - to 10 -fold higher incidence of autoimmune/inflammatory diseases seen in females of all mammalian species. During inflammation, cytokines from the periphery activate the central nervous system through multiple routes. This results in stimulation of the hypothalamic-pituitary-adrenal axis which, in turn through the immunosuppressive effects of the glucocorticoids, generally inhibits inflammation. Recent studies indicate that physiological levels of glucocorticoids are immunomodulatory rather than solely immunosuppressive, causing a shift in patterns of cytokine production from
\end{abstract}

a TH1- to a TH2-type pattern. Interruptions of this loop at any level and through multiple mechanisms, whether genetic, or through surgical or pharmacological interventions, can render an inflammatory resistant host susceptible to inflammatory disease. Over-activation of this axis, as occurs during stress, can also affect severity of infectious disease through the immunosuppressive effects of the glucocorticoids. These interactions have been clearly demonstrated in many animal models, across species, strains and diseases, and are also relevant to human inflammatory, autoimmune and allergic illnesses, including rheumatoid arthritis, systemic lupus erythematosus, Sjogren's syndrome, allergic asthma and atopic skin disease. While many genes and environmental factors contribute to susceptibility and resistance to autoimmune/ inflammatory diseases, a full understanding of the molecular effects on immune responses of combinations of neuropeptides, neurohormones and neurotransmitters at all levels has opened up new therapeutic approaches and are essential for the design of future therapies based on such principles.

Journal of Endocrinology (2001) 169, 429-435

\section{Introduction}

Interactions between the immune and nervous systems play an important role in modulating host susceptibility and resistance to inflammatory and infectious diseases (Sternberg 1997a). Many, but not all, of the regulatory effects of the neuroendocrine stress response on immunemediated diseases occur through the actions of the glucocorticoid hormones on immune cell functions. Neuroendocrine regulation of inflammatory and immune responses and disease occurs at multiple levels: systemically, through the anti-inflammatory action of glucocorticoids released via hypothalamic-pituitary-adrenal axis stimulation; regionally, through local production of glucocorticoids in immune organs such as the thymus; locally, at sites of inflammation, through release of usually proinflammatory neuropeptides and neurohormones from peripheral nerves. Neural regulation of immune responses also occurs regionally through sympathetic nervous system activation and the effects of neurotransmitters such as norepinephrine on immune cells in spleen and lymph nodes. Estrogen also plays an important role in immune modulation, and contributes to the approximately two- to tenfold higher incidence of autoimmune/inflammatory diseases seen in females of all mammalian species (Wilder \& Sternberg 1990, Ahmed et al. 1999). Many other hormones also regulate immune responses, including prolactin, thyroid hormone, growth hormone, insulin-like growth factor-I (Dorshkind \& Horseman 2000) and androgens (Kocar et al. 2000). It has been suggested that rather than pure immunoregulators, many of these act as anabolic and stress-modulating hormones in many tissues, including the immune system (Dorshkind \& Horseman 2000). 
During inflammation, a bi-directional signaling between the immune and central nervous system (CNS) is set into play, in which cytokines from the periphery can initiate the cycle by crossing the blood-brain barrier actively or at leaky sites in the blood-brain barrier, the circumventricular organs. They can also activate cerebral endothelial cell second messenger systems, including nitric oxide synthase and cyclooxygenase, and thus indirectly stimulate CNS functions. In addition, cytokines such as interleukin-1 (IL-1) can signal the central nervous system through stimulation of the vagus nerve and activation of brainstem regions such as the nucleus of the tractus solitarius (Bluthe et al. 1994, Watkins et al. 1994). Such immune signaling of the CNS causes activation of the hypothalamic-pituitary-adrenal (HPA) axis, with release of corticotropin releasing hormone $(\mathrm{CRH})$ from the hypothalamus and adrenocorticotropin (ACTH) from the pituitary gland which, in turn through the generally immunosuppressive effects of the glucocorticoids released from the adrenals, inhibits inflammation.

Both excess or inadequate stress hormone responses are associated with disease: excess with enhanced susceptibility to infection, and inadequate stress hormone responses with enhanced susceptibility to inflammatory, autoimmune and allergic diseases. Thus, chronic HPA axis over-activation, as occurs during stress, can affect susceptibility to or severity of infectious disease through the immunosuppressive effects of the glucocorticoids (Brown et al. 1993, Hermann et al. 1993, Glaser \& Kiecolt-Glaser 1998). In contrast, blunted HPA axis responses are associated with enhanced susceptibility to autoimmune inflammatory disease (Sternberg 1997b, Jafarian-Tehrani \& Sternberg 1999).

\section{Neuroendocrine regulation of inflammation through actions of the glucocorticoids}

\section{Hypothalamic-pituitary-adrenal axis}

The HPA axis modulates inflammation through the generally anti-inflammatory action of glucocorticoids released from the adrenal cortex after HPA axis stimulation. Initially, glucocorticoids were thought to have a mainly immunosuppressive effect (Hench et al. 1950, Cupps \& Fauci 1982). Indeed, pharmacological doses of glucocorticoids are immunosuppressive at virtually every level of immune and inflammatory responses, including during activation of the innate immune response and in both cellular and humoral acquired immune responses. Thus, glucocorticoids suppress cell adhesion, margination and migration, macrophage activation, antigen presentation, $\mathrm{T}$ cell receptor expression, $\mathrm{T}$ lymphocyte activation, proliferation, differentiation and mature cell function, including cytotoxicity, and B cell function including antibody production. Recent studies, however, indicate that physiological levels of glucocorticoids are immunomodulatory rather than solely immunosuppressive, causing a shift of cytokine production from a primarily pro-inflammatory to an anti-inflammatory pattern (Elenkov \& Chrousos 1999, Ashwell et al. 2000). Such patterns of cytokine production can be categorized as TH1 or TH2, and roughly correspond to cellular or humoral patterns of immune responses respectively. A TH1 pattern of cytokines is characterized by production of largely pro-inflammatory IL-2 and interferon gamma (IFN $\gamma$ ), with a primarily cellular immune response. A TH2 pattern of immunity is characterized by production of IL-4 and IL-10, and is associated with a primarily humoral or antibody response. At physiological concentrations, glucocorticoids inhibit TH1 and enhance TH2 cytokine production (Elenkov \& Chrousos 1999, Franchimont et al. 2000) thus shifting immune responses from a TH1 to a TH2 pattern.

A functional glucocorticoid receptor is required for glucocorticoids to exert their effects on immune cell function, although some of these effects may not require receptor dimerization and DNA binding of the receptor but may occur primarily through protein-protein interactions (Kellendonk et al. 1999).

\section{Intra-thymic glucocorticoid synthesis and T cell selection}

Glucocorticoids also regulate immune function at the level of immune organs such as the thymus. The entire synthetic enzyme machinery for glucocorticoid production has been identified in the thymus, as have glucocorticoid hormones and their precursors (Vacchio \& Ashwell 1997). Studies show that these local glucocorticoids play a role in thymic T cell selection. Depending on the concentration of glucocorticoid produced relative to the concentration of antigen, $\mathrm{T}$ cells undergo negative or positive selection, that is they may be shunted to the death pathway and die by apoptosis or they may undergo clonal proliferation. Thymic glucocorticoids are produced by thymic cytokeratin expressing stromal cells, rather than by differentiating $\mathrm{T}$ cells. The amount of steroid produced within the thymus is unknown but low compared to amounts present in plasma, and can be detected only in tissue culture, suggesting that the steroid effects on thymic selection are paracrine rather than endocrine in nature. It is not known whether this local glucocorticoid production is under hypothalamic-pituitary control or is independent. Thus, it is not known whether circadian or stressrelated variations in ACTH can affect this route of glucocorticoid-related thymic selection.

\section{Local and regional immune regulation by the nervous system}

In addition to regional glucocorticoid synthesis, the nervous system regulates the immune system regionally 
through innervation of immune organs by the sympathetic nervous system and at local sites of inflammation through the peripheral nerves. Catecholamines, in particular adrenalin, have been shown to affect TH1 and TH2 patterns of cytokine production profiles (Elenkov \& Chrousos 1999).

\section{Regional immune regulation in immune organs}

The spleen, thymus and lymph nodes all show thyrosine hydroxylase and other neuropeptide-expressing positive nerve endings, including calcitonin gene-related peptide (CGRP), in close apposition to lymphoid cells (Tollefson \& Bulloch 1990, Bellinger et al. 1992, 1997). That such innervation plays an important role in immune cell function is evidenced in studies in which cutting sympathetic innervation to the spleen is associated with blunted splenocyte function. A similar blunting of immune cell function is associated with dying back of splenic sympathetic innervation during aging (Madden et al. 1997). In these studies, treatment with the irreversible monoamine oxidase-B (MAO-B) inhibitor, deprenyl, was associated with both regeneration of sympathetic nerve endings and re-constitution of splenocyte activity (ThyagaRajan et al. 1998).

\section{Local immune regulation at sites of inflammation}

The nervous system also regulates the immune system locally at sites of inflammation through release of neuropeptides and neurohormones from peripheral nerves. These are usually pro-inflammatory. Thus, substance P and $\mathrm{CRH}$ have been shown to be associated with increased histamine release from mast cells, and CRH has been shown to be expressed at sites of inflammation, such as inflamed synovium in experimental rodent inflammatory arthritis and in human rheumatoid arthritis (Agro \& Stanisz 1992, Crofford et al. 1992).

\section{Effects of excess stress response activation on immune function and disease}

Physiological changes in circulating glucocorticoid levels are associated with shifts in patterns of immune cytokine production. Thus, the moderate elevations in cortisol in the range of $375 \mathrm{nmol} / 1$ that occur during the morning circadian rise in cortisol, or stress elevations in the range of $950 \mathrm{nmol} / 1$ that occur after exercise on a treadmill have differential effects on production of cytokines such as tumor necrosis factor-alpha (TNF $\alpha$ ), IL-1 and IL-6. In these studies, whole blood collected from subjects at rest, from subjects treated with different doses of hydrocortisone, or from subjects during and 20 minutes after exercise, was incubated with bacterial lipopolysaccharide (LPS) ex vivo, and cytokine production was quantitated in cultured supernantants (DeRijk et al. 1996, 1997). Different cytokines exhibited different degrees of sensitivity to suppression by glucocorticoids under these physiological conditions. At lower evening cortisol levels, the cytokines IL-6, TNF $\alpha$ and IL-1 were equally produced in response to the pro-inflammatory LPS stimulus, while at higher morning levels and with stress levels produced during exercise, relative amounts of these cytokines shifted. At high stress levels of glucocorticoids, IL-6 remained relatively resistant to glucocorticoid suppression while IL-1 and TNF $\alpha$ were significantly suppressed. This exquisite sensitivity of cytokine production and pattern to physiological changes in glucocorticoid levels suggests that under situations of chronic stress there may indeed be profound effects of stress hormones on immune responses and subsequent disease susceptibility.

Indeed, physical and psychological stress have been shown to impair immune responses and increase susceptibility to and severity of infection in animal models (Brown et al. 1993, Hermann et al. 1993). In these circumstances, the overall effect of glucocorticoids on disease severity and outcome is determined by the relative contribution of host inflammatory responses versus pathogen effects in the pathogenesis of the infectious illness (Brown \& Zwilling 1994, Hermann et al. 1995, Ruzek et al. 1999). For example, in pulmonary viral infections in which the damage is primarily produced by pulmonary inflammatory infiltrates in response to the virus, elevated glucocorticoids and adrenergic responses such as occur during stress actually suppress mononuclear cell infiltrates into lung and draining lymph nodes. In such situations, blocking both glucocorticoid and sympathetic responses reconstitutes mononuclear infiltrates in draining lymph nodes and lungs of influenza-infected mice (Hermann et al. 1995). However, in situations such as mycobacteria tuberculosis infection, glucocorticoid treatment accelerated decay of the mycobacteria resistance factor Nramp mRNA, thus contributing to enhanced susceptibility to mycobacterial infection (Brown et al. 1997). Such glucocorticoid effects could explain the association of exacerbation or systemic spread of mycobacteria tuberculosis infection during stress or with glucocorticoid treatment. Furthermore, the effects of stress levels of glucocorticoids differs depending on the type of immune exposure (irritant versus pathogen) and the timing of the stress in relation to the exposure. Recent studies in rodent contact dermatitis show that acute stress early on actually enhances rather than suppresses immune responses in contact dermatitis (Dhabhar 1998, Dhabhar et al. 2000).

In humans with chronic or sub-acute severe stress, glucocorticoid elevations have been associated with suppression of a variety of aspects of immune responses and increased susceptibility to infectious illnesses. Specific situations studied include chronic care-givers of Alzheimer's patients, students undergoing exam stress, couples undergoing marital conflict or Army Rangers 
experiencing extremes of exercise, temperature and nutritional stress during training. These stress situations have been associated with enhanced susceptibility to viral infection, prolonged wound healing or decreased antibody production to vaccination (Kramer et al. 1997, Glaser \& Kiecolt-Glaser 1998, Rozlog et al. 1999, Vedhara et al. 1999, Wu et al. 1999, Friedl et al. 2000).

\section{Effects of blunted HPA axis responses on immune function and susceptibility to inflammatory disease}

The association between a blunted HPA axis and susceptibility to autoimmune/inflammatory disease has been clearly shown in many animal models, across species, strains and diseases, in chickens (Wick et al. 1993), mice (Lechner et al. 1996) and rats (Sternberg et al. 1989a,b, Jafarian-Tehrani \& Sternberg 1999). Lewis (LEW/N) rats are an inbred strain of rats that are highly susceptible to a wide variety of autoimmune inflammatory diseases, at least in part due to their blunted HPA axis responses. Histocompatible Fischer $(\mathrm{F} 344 / \mathrm{N})$ rats, in contrast, show a hyperactive HPA axis response and are relatively resistant to the same autoimmune inflammatory diseases (Sternberg et al. 1989a,b). Interruptions of the HPA axis at any level and through multiple mechanisms, whether on a genetic basis, through surgical means such as adrenalectomy or hypophysectomy, or with pharmacological interventions such as treatment with the glucocorticoid receptor antagonist RU 486, can render an inflammatory resistant host susceptible to inflammatory disease (Sternberg 1997a,b). In these circumstances, exposure to the pro-inflammatory stimulus results in high mortality exposure from septic shock within 12 hours (Sternberg et al. 1989a, Mason et al. 1990, Edwards et al. 1991). Conversely, transplantation of fetal hypothalamic tissue from inflammatory resistant F344/N rats into the third ventricle of inflammatory susceptible LEW/N rats reverses both the $\mathrm{LEW} / \mathrm{N}$ peripheral inflammatory susceptibility and their blunted HPA axis responses to bacterial LPS (Misiewicz et al. 1997).

The association between a blunted HPA axis and autoimmune, inflammatory and allergic diseases is also relevant to humans with illnesses including rheumatoid arthritis (Neeck et al. 1990, Cash et al. 1992, Chikanza et al. 1992, Cutolo et al. 1999, Gutierrez et al. 1999), systemic lupus erythematosus (Gutierrez et al. 1998), Sjogren's syndrome (Johnson et al. 1998), allergic asthma and atopic skin disease (Buske-Kirschbaum et al. 1997), fibromyalgia (Crofford et al. 1994) and chronic fatigue syndrome (Demitrack et al. 1991). However, it may not be necessary for the HPA axis defect to occur centrally, at the level of the hypothalamus or pituitary, to predispose to enhanced susceptibility to autoimmune/inflammatory disease. The overall effect of inappropriately low glucocorticoid clamping of immune responses may result not only from low circulating glucocorticoids, but also from abnormalities of glucocorticoid receptor function. Thus, in experimental animal models in which defective glucocorticoid receptors are expressed, enhancement of innate and acquired immune cell responses have been shown (Kellendonk et al. 1999). In humans with quiescent Crohn's disease, peripheral blood mononuclear cells show a decreased sensitivity to glucocorticoid suppression of LPS-induced cytokine production (Franchimont et al. 1999).

\section{Relationship between sympathetic dysregulation and autoimmune disease}

Imbalances of sympathetic nervous system responses are also associated with autoimmune inflammatory diseases such as arthritis in both humans and rodents. Human juvenile rheumatoid arthritis has been associated with both abnormal HPA axis and sympathoneuronal responses (Kuis et al. 1996). Inflammatory susceptible $\mathrm{LEW} / \mathrm{N}$ rats show not only blunted HPA axis responsiveness, but also blunted sympathoneuronal activity in response to glucoprivic stress (Goldstein et al. 1993). This raises the question of whether in such susceptible hosts multiple factors may account for overall susceptibility to autoimmune/ inflammatory disease.

\section{Genetics of autoimmune/inflammatory disease susceptibility}

Both animal and human studies of genetic regulation of autoimmune inflammatory diseases such as inflammatory arthritis indicate that these diseases are polygenic and multigenic - that is, many genes each with a small effect play a role in determining genetic susceptibility to inflammatory disease (Griffiths et al. 1999). In genetic linkage and segregation studies in inbred rat strains at least 20 different loci on 15 different chromosomes have been shown to link with inflammatory arthritis (Wilder et al. 1999). Two of these loci, one on chromosome 2 and one on chromosome 10, link to a sub-trait of complex inflammatory disease, the innate inflammatory response to carrageenan (Listwak et al. 1999). Several genes within the chromosome 10 linkage region regulate both inflammation and the neuroendocrine stress response, including the genes for angiotensin converting enzyme (ACE) and CRH receptor type 1 (CRHR1).

Sequencing of the coding regions of these genes in the parental strains used in this intercross indicated no difference between LEW/N and F344/N rats in the CRHR1, and a point mutation in ACE resulting in a leucine to phenylalanine switch near the $\mathrm{N}$-terminal active site of the enzyme (Jafarian-Tehrani et al. 2000). Further analysis revealed that while the non-specific activity of ACE was 
elevated in the strain that showed the mutation (F344/N rats), there was no difference between the two strains in specific activity of the enzyme, and treatment of the rats with ACE inhibitors did not affect the inflammatory phenotype.

Thus, while such linkage and segregation studies may be useful in guiding studies towards a particular chromosomal region, even potentially interesting candidate genes showing mutations may alone not account for expression of traits of interest. This may be because susceptibility is related to inheritance of multiple genes and regions of DNA, as has been shown in mouse models of systemic lupus erythematosus (SLE), in which four regions on four different chromosomes have been identified that are additive in determining final expression of disease (Wakeland et al. 1999).

Finally, in such complex autoimmune diseases, there is also a large environmental component that determines disease expression. For example, for the innate carrageenan inflammatory trait, the relative contribution of environmental to genetic factors to the variance of the trait was approximately $65 \%$ environmental to $35 \%$ genetic (Listwak et al. 1999).

The multiplicity of genes that regulate inflammatory disease susceptibility suggests that it would be unlikely that any single factor, including any individual transcription factor or nuclear receptor alone, will determine susceptibility to complex autoimmune inflammatory diseases. It may be that in certain individuals or diseases one or more of these factors may contribute to predisposition to the overall susceptibility and severity of disease expression.

\section{Sex hormones}

While this review has focused on the HPA axis and glucocorticoids and their role in susceptibility to inflammatory disease, estrogen is known to play an extremely important role in immune modulation, and contributes to the approximately two- to tenfold higher ratio of most autoimmune diseases in females of all species (Wilder \& Sternberg 1990, Ahmed et al. 1999, Lahita 1999). Ovariectomy has been shown to reduce, while replacement of estrogen re-constitutes, this differential susceptibility to experimental inflammatory arthritis in rodents (Allen et al. 1983). Furthermore, gender, menstrual cycle and estrogen replacement therapy have all been shown to affect HPA axis (Kirschbaum et al. 1999) and immune (Zelazowska et al. 1997) function in human studies.

\section{Conclusions and therapeutic implications}

A full understanding of the molecular effects on immune responses of combinations of neuropeptides, neurohormones and neurotransmitters at all levels in these interactions is essential for design of future therapies based on such principles. Thus, pharmaceutical agents developed as neuropeptide antagonists may have an overall antiinflammatory effect on immune disease if their predominant effect is at a local level at inflammatory sites, or might have a pro-inflammatory effect if their major site of action is blockade of glucocorticoid immunosuppression. Nonetheless, a detailed understanding of these neuroendocrineimmune interactions has opened up new therapeutic approaches to the treatment of autoimmune/inflammatory disease and has led to the recognition that glucocorticoids play a physiological as well as a pharmacological role in regulating inflammation.

\section{References}

Agro A \& Stanisz AM 1992 Are lymphocytes a target for substance P modulation in arthritis? Seminars in Arthritis and Rheumatism 21 252-258.

Ahmed SA, Hissong BD, Verthelyi D, Donner K, Becker K \& Karpuzoglu-Sahin E 1999 Gender and risk of autoimmune diseases: possible role of estrogenic compounds. Environmental Health Perspectives 107 (Suppl 5) 681-684.

Allen JB, Blatter D, Calandra GB \& Wilder RL 1983 Sex hormonal effects on the severity of streptococcal cell wall-induced polyarthritis in the rat. Arthritis and Rheumatism 26 560-563.

Ashwell JD, Lu FW \& Vacchio MS 2000 Glucocorticoids in T cell development and function. Annual Review of Immunology 18 309-345.

Bellinger DL, Lorton D, Felten SY \& Felten DL 1992 Innervation of lymphoid organs and implications in development, aging and autoimmunity. International Journal of Immunopharmacology 14 329-344.

Bellinger DL, Lorton D, Horn L, Brouxhon S, Felten SY \& Felten DL 1997 Vasoactive intestinal polypeptide (VIP) innervation of rat spleen, thymus, and lymph nodes. Peptides 18 1139-1149.

Bluthe RM, Walter V, Parnet P, Laye S, Lestage J, Verrier D, Poole S, Stenning BE, Kelley KW \& Dantzer R 1994 Lipopolysaccharide induces sickness behaviour in rats by a vagal mediated mechanism. Comptes Rendus de l'Academie des Sciences. Serie III, Sciences de la Vie 317 499-503.

Brown DH \& Zwilling BS 1994 Activation of the hypothalamicpituitary-adrenal axis differentially affects the anti-mycobacterial activity of macrophages from BCG-resistant and susceptible mice. Journal of Neuroimmunology 53 181-187.

Brown DH, Sheridan J, Pearl D \& Zwilling BS 1993 Regulation of mycobacterial growth by the hypothalamus-pituitary-adrenal axis: differential responses of Mycobacterium bovis BCG-resistant and -susceptible mice. Infection and Immunity 61 4793-4800.

Brown DH, Lafuse WP \& Zwilling BS 1997 Stabilized expression of mRNA is associated with mycobacterial resistance controlled by Nramp1. Infection and Immunity 65 597-603.

Buske-Kirschbaum A, Jobst S, Psych D, Wustmans A, Kirschbaum C, Rauh W \& Hellhammer D 1997 Attenuated free cortisol response to psychosocial stress in children with atopic dermatitis. Psychosomatic Medicine 59 419-426.

Cash JM, Crofford LJ, Gallucci WT, Sternberg EM, Gold PW, Chrousos GP \& Wilder RL 1992 Pituitary-adrenal axis responsiveness to ovine corticotropin releasing hormone in patients with rheumatoid arthritis treated with low dose prednisone. Journal of Rheumatology 19 1692-1696.

Chikanza IC, Petrou P, Kingsley G, Chrousos G \& Panayi GS 1992 Defective hypothalamic response to immune and inflammatory 
stimuli in patients with rheumatoid arthritis. Arthritis and Rheumatism 35 1281-1288.

Crofford LJ, Sano H, Karalis K, Webster EL, Goldmuntz EA, Chrousos GP \& Wilder RL 1992 Local secretion of corticotropin-releasing hormone in the joints of Lewis rats with inflammatory arthritis. Journal of Clinical Investigation 90 2555-2564.

Crofford LJ, Pillemer SR, Kalogeras KT, Cash JM, Michelson D, Kling MA, Sternberg EM, Gold PW, Chrousos GP \& Wilder RL 1994 Hypothalamic-pituitary-adrenal axis perturbations in patients with fibromyalgia. Arthritis and Rheumatism 37 1583-1592.

Cupps TR \& Fauci AS 1982 Corticosteroid-mediated immunoregulation in man. Immunological Reviews 65 133-155.

Cutolo M, Foppiani L, Prete C, Ballarino P, Sulli A, Villaggio B, Seriolo B, Giusti M \& Accardo S 1999 Hypothalamicpituitary-adrenocortical axis function in premenopausal women with rheumatoid arthritis not treated with glucocorticoids. Journal of Rheumatology 26 282-288.

Demitrack MA, Dale JK, Straus SE, Laue L, Listwak SJ, Kruesi MJ, Chrousos GP \& Gold PW 1991 Evidence for impaired activation of the hypothalamic-pituitary-adrenal axis in patients with chronic fatigue syndrome. Journal of Clinical Endocrinology and Metabolism $\mathbf{7 3}$ 1224-1234.

DeRijk RH, Petrides J, Deuster P, Gold PW \& Sternberg EM 1996 Changes in corticosteroid sensitivity of peripheral blood lymphocytes after strenuous exercise in humans. Journal of Clinical Endocrinology and Metabolism 81 228-235.

DeRijk R, Michelson D, Karp B, Petrides J, Galliven E, Deuster P, Paciotti G, Gold PW \& Sternberg EM 1997 Exercise and circadian rhythm-induced variations in plasma cortisol differentially regulate interleukin-1 beta (IL-1 beta), IL-6, and tumor necrosis factor-alpha (TNF alpha) production in humans: high sensitivity of TNF alpha and resistance of IL-6. Journal of Clinical Endocrinology and Metabolism 82 2182-2191.

Dhabhar FS 1998 Stress-induced enhancement of cell-mediated immunity. Annals of the New York Academy of Sciences 840 359-372.

Dhabhar FS, Satoskar AR, Bluethmann H, David JR \& McEwen BS 2000 Stress-induced enhancement of skin immune function: a role for gamma interferon. PNAS 97 2846-2851.

Dorshkind K \& Horseman ND 2000 The roles of prolactin, growth hormone, insulin-like growth factor-I, and thyroid hormones in lymphocyte development and function: insights from genetic models of hormone and hormone receptor deficiency. Endocrine Reviews 21 292-312.

Edwards CKI, Yunger LM, Lorence RM, Dantzer R \& Kelley KW 1991 The pituitary gland is required for protection against lethal effects of Salmonella typhimurium. PNAS 88 2274-2277.

Elenkov IJ \& Chrousos GP 1999 Stress hormones, TH1/TH2 patterns, pro/anti-inflammatory cytokines and susceptibility to disease. Trends in Endocrinology and Metabolis 10 359-368.

Franchimont D, Louis E, Dupont P, Vrindts-Gevaert Y, Dewe W, Chrousos G, Geenen V \& Belaiche J 1999 Decreased corticosensitivity in quiescent Crohn's disease: an ex vivo study using whole blood cell cultures. Digestive Diseases and Sciences 44 1208-1215.

Franchimont D, Galon J, Gadina M, Visconti R, Zhou Y, Aringer M, Frucht DM, Chrousos GP \& O'Shea JJ 2000 Inhibition of TH1 immune response by glucocorticoids: dexamethasone selectively inhibits IL-12-induced Stat4 phosphorylation in T lymphocytes. Journal of Immunology 164 1768-1774.

Friedl KE, Moore RJ, Hoyt RW, Marchitelli LJ, Martinez-Lopez LE \& Askew EW 2000 Endocrine markers of semistarvation in healthy lean men in a multistressor environment. Journal of Applied Physiology 88 1820-1830.

Glaser R \& Kiecolt-Glaser JK 1998 Stress-associated immune modulation: relevance to viral infections and chronic fatigue syndrome. American Journal of Medicine 105 S35-S42.
Goldstein DS, Garty M, Bagdy G, Szemeredi K, Sternberg EM, Listwak S, Pacak K, Deka-Starosta A, Hoffman A, Chang PC et al. 1993 Role of CRH in glucopenia-induced adrenomedullary activation in rats. Journal of Neuroendocrinology 5 475-486.

Griffiths MM, Encinas JA, Remmers EF, Kuchroo VK \& Wilder RL 1999 Mapping autoimmunity genes. Current Opinion in Immunology 11 689-700.

Gutierrez MA, Garcia ME, Rodriguez JA, Rivero S \& Jacobelli S 1998 Hypothalamic-pituitary-adrenal axis function and prolactin secretion in systemic lupus erythematosus. Lupus 7 404-408.

Gutierrez MA, Garcia ME, Rodriguez JA, Mardonez G, Jacobelli S \& Rivero S 1999 Hypothalamic-pituitary-adrenal axis function in patients with active rheumatoid arthritis: a controlled study using insulin hypoglycemia stress test and prolactin stimulation. Journal of Rheumatology 26 277-281.

Hench PS, Kendall EC, Slocumb CH \& Polley HF 1950 Effects of cortisone acetate and pituitary ACTH on rheumatoid arthritis, rheumatic fever and certain other conditions. Archives of Internal Medicine 85545-666.

Hermann G, Tovar CA, Beck FM, Allen C \& Sheridan JF 1993 Restraint stress differentially affects the pathogenesis of an experimental influenza viral infection in three inbred strains of mice. Journal of Neuroimmunology 47 83-94.

Hermann G, Beck FM \& Sheridan JF 1995 Stress-induced glucocorticoid response modulates mononuclear cell trafficking during an experimental influenza viral infection. Journal of Neuroimmunology 56 179-186.

Jafarian-Tehrani M \& Sternberg EM 1999 Animal models of neuroimmune interactions in inflammatory diseases. Journal of Neuroimmunology 100 13-20.

Jafarian-Tehrani M, Listwak S, Barrientos RM, Michaud A, Corvol P \& Sternberg EM 2000 Exclusion of angiotensin I-converting enzyme as a candidate gene involved in exudative inflammatory resistance in F344/N rats. Molecular Medicine 6 319-331.

Johnson EO, Vlachoyiannopoulos PG, Skopouli FN, Tzioufas AG \& Moutsopoulos HM 1998 Hypofunction of the stress axis in Sjogren's syndrome. Journal of Rheumatology 25 1508-1514.

Kellendonk C, Tronche F, Reichardt HM \& Schutz G 1999 Mutagenesis of the glucocorticoid receptor in mice. Journal of Steroid Biochemistry and Molecular Biology 69 253-259.

Kirschbaum C, Kudielka BM, Gaab J, Schommer NC \& Hellhammer DH 1999 Impact of gender, menstrual cycle phase, and oral contraceptives on the activity of the hypothalamus-pituitary-adrenal axis. Psychosomatic Medicine 61 154-162.

Kocar IH, Yesilova Z, Ozata M, Turan M, Sengul A \& Ozdemir I 2000 The effect of testosterone replacement treatment on immunological features of patients with Klinefelter's syndrome. Clinical and Experimental Immunology 121 448-452.

Kramer TR, Moore RJ, Shippee RL, Friedl KE, Martinez-Lopez L, Chan MM \& Askew EW 1997 Effects of food restriction in military training on T-lymphocyte responses. International Journal of Sports Medicine 18 (Suppl 1) S84-S90.

Kuis W, de Jong-de Vos van Steenwijk C, Sinnema G, Kavelaars A, Prakken B, Helders P \& Heijnen CJ 1996 The autonomic nervous system and the immune system in juvenile rheumatoid arthritis. Brain, Behavior and Immunity 10 387-398.

Lahita RG 1999 The role of sex hormones in systemic lupus erythematosus. Current Opinion in Rheumatology 11 352-356.

Lechner O, Hu Y, Jafarian-Tehrani M, Dietrich H, Schwarz S, Herold M, Haour F \& Wick G 1996 Disturbed immunoendocrine communication via the hypothalamo-pituitary-adrenal axis in murine lupus. Brain, Behavior and Immunity 10 337-350.

Listwak S, Barrientos RM, Koike G, Ghosh S, Gomez M, Misiewicz B \& Sternberg EM 1999 Identification of a novel inflammation-protective locus in the Fischer rat. Mammalian Genome $10362-365$. 
Madden KS, Rajan S, Bellinger DL, Felten SY \& Felten DL 1997 Age-associated alterations in sympathetic neural interactions with the immune system. Developmental and Comparative Immunology 21 479-486.

Mason D, MacPhee I \& Antoini F 1990 The role of the neuroendocrine system in determining genetic susceptibility to experimental allergic encephalomyelitis in the rat. Immunology $\mathbf{7 0}$ $1-5$.

Misiewicz B, Poltorak M, Raybourne RB, Gomez M, Listwak S \& Sternberg EM 1997 Intracerebroventricular transplantation of embryonic neuronal tissue from inflammatory resistant into inflammatory susceptible rats suppresses specific components of inflammation. Experimental Neurology 146 305-314.

Neeck G, Federlin K, Graef V, Rusch D \& Schmidt KL 1990 Adrenal secretion of cortisol in patients with rheumatoid arthritis. Journal of Rheumatology 17 24-29.

Rozlog LA, Kiecolt-Glaser JK, Marucha PT, Sheridan JF \& Glaser R 1999 Stress and immunity: implications for viral disease and wound healing. Journal of Periodontology 70 786-792.

Ruzek MC, Pearce BD, Miller AH \& Biron CA 1999 Endogenous glucocorticoids protect against cytokine-mediated lethality during viral infection. Journal of Immunology 162 3527-3533.

Sternberg EM 1997a Emotions and disease: from balance of humors to balance of molecules. Nature Medicine 3 264-267.

Sternberg EM $1997 b$ Neural-immune interactions in health and disease. Journal of Clinical Investigation 100 2641-2647.

Sternberg EM, Hill JM, Chrousos GP, Kamilaris T, Listwak SJ, Gold PW \& Wilder RL 1989a Inflammatory mediator-induced hypothalamic-pituitary-adrenal axis activation is defective in streptococcal cell wall arthritis-susceptible Lewis rats. PNAS $\mathbf{8 6}$ 2374-2378.

Sternberg EM, Young WS, Bernardini R, Calogero AE, Chrousos GP, Gold PW \& Wilder RL 1989b A central nervous system defect in biosynthesis of corticotropin-releasing hormone is associated with susceptibility to streptococcal cell wall-induced arthritis in Lewis rats. PNAS 86 4771-4775.

ThyagaRajan S, Felten SY \& Felten DL 1998 Restoration of sympathetic noradrenergic nerve fibers in the spleen by low doses of L-deprenyl treatment in young sympathectomized and old Fischer 344 rats. Journal of Neuroimmunology 81 144-157.

Tollefson L \& Bulloch K 1990 Dual-label retrograde transport: CNS innervation of the mouse thymus distinct from other mediastinum viscera. Journal of Neuroscience Research 25 20-28.
Vacchio MS \& Ashwell JD 1997 Thymus-derived glucocorticoids regulate antigen-specific positive selection. Journal of Experimental Medicine 185 2033-2038.

Vedhara K, Cox NK, Wilcock GK, Perks P, Hunt M, Anderson S, Lightman SL \& Shanks NM 1999 Chronic stress in elderly carers of dementia patients and antibody response to influenza vaccination. Lancet 353 627-631.

Wakeland EK, Wandstrat AE, Liu K \& Morel L 1999 Genetic dissection of systemic lupus erythematosus. Current Opinion in Immunology 11 701-707.

Watkins LR, Wiertelak EP, Goehler LE, Mooney HK, Martinez J, Furness L, Smith KP \& Maier SF 1994 Neurocircuitry of illness-induced hyperalgesia. Brain Research 639 283-299.

Wick G, Hu Y, Schwarz S \& Kroemer G 1993 Immunoendocrine communication via the hypothalamo-pituitary-adrenal axis in autoimmune diseases. Endocrine Reviews 14 539-563.

Wilder RL \& Sternberg EM 1990 Neuroendocrine hormonal factors in rheumatoid arthritis and related conditions. Current Opinion in Rheumatology 2 436-440.

Wilder RL, Griffiths MM, Remmers EF, Cannon GW, Caspi RR, Kawahito Y, Gulko PS, Longman RE, Dracheva SV, Du Y et al. 1999 Localization in rats of genetic loci regulating susceptibility to experimental erosive arthritis and related autoimmune diseases. Transplantation Proceedings 31 1585-1588.

Wu H, Wang J, Cacioppo JT, Glaser R, Kiecolt-Glaser JK \& Malarkey WB 1999 Chronic stress associated with spousal caregiving of patients with Alzheimer's dementia is associated with downregulation of B-lymphocyte GH mRNA. Journals of Gerontology. Series A, Biological Sciences and Medical Sciences $\mathbf{5 4}$ M212-M215.

Zelazowska EB, Singh A, Raybourne RB, Sternberg EM, Gold PW \& Deuster PA 1997 Lymphocyte subpopulation expression in women: effect of exercise and circadian rhythm [published erratum appears in Medicine and Science in Sports and Exercise 1997 29 846]. Medicine and Science in Sports and Exercise 29 467-473.

Received in final form 30 January 2001 Accepted 1 February 2001 